\title{
Bone Marrow Aspiration
}

National Cancer Institute

\section{Source}

National Cancer Institute. Bone Marrow Aspiration. NCI Thesaurus. Code C15644.

Aspiration of immature hematopoietic elements and blood from the bone marrow. It is done for the evaluation of hematopoietic disorders and for the evaluation of infectious diseases and cytogenetic studies. 